\title{
Survei IoT Healthcare Device
}

\author{
Yulia Suryandari \\ Sekolah Teknik Elektro dan Informatika \\ Institut Teknologi Bandung \\ Bandung, Indonesia \\ yulia.suryandari@students.itb.ac.id
}

\begin{abstract}
The Internet of Things (IoT) has enormous potential in creating the value of life related to technology. IoT has various application domains, including in the health sector. IoT-based healthcare services are expected to reduce costs, improve quality of life, and enrich user experience. The presence of IoT devices for healthcare services can also avoid unnecessary hospitalization and ensure that patients who need health services get it quickly. This paper surveys advances in IoT-based health care technology and reviews the latest architectures / platforms, platforms, applications and industry trends in IoT-based healthcare solutions. Some IoT devices and prototypes in the healthcare field are also discussed in this paper. Through this paper, it is expected that readers can be known and discuss IoT devices in the healthcare sector.
\end{abstract}

Keywords-IoT, healthcare, device

\section{PENDAHULUAN}

Internet of Things (IoT) telah menjadi topik hangat yang dibicarakan akhir-akhir ini. IoT memiliki potensi yang sangat besar dalam menciptakan nilai kehidupan berkaitan dengan teknologi. Hal ini menjadi tren yang terus berkembang karena IoT tidak hanya menjadi suatu konsep yang mempengaruhi hidup manusia, namun bagaimana IoT bisa membantu memudahkan kehidupan manusia. dimana semua perangkat dapat mengambil manfaat dari koneksi yang terhubung satu sama lain dengan cara yang cerdas, hemat energi, dan hemat biaya [1].

Perkembangan perangkat dengan kemampuan komunikasi aktif semakin mendekatkan keberadaan IoT, dimana fungsi penginderaan dan aktuasi dengan mudah berbaur dengan berbagai sumber informasi baru. Evolusi sistem bergerak generasi berikutnya akan tergantung pada kreativitas pengguna dalam mendesain aplikasi baru. IoT adalah teknologi yang ideal untuk mempengaruhi domain ini dengan menyediakan data baru yang berkembang dan sumber daya komputasi yang diperlukan untuk membuat aplikasi terbaru [2].

IoT mulai dikembangkan pada bidang kesehatan untuk meningkatkan kualitas hidup. Dalam beberapa tahun terakhir, bidang ini telah menarik perhatian luas dari para peneliti untuk membahas potensi IoT di bidang perawatan kesehatan dengan mempertimbangkan berbagai tantangan praktis [3]. Hal itu dapat terlihat dengan banyaknya aplikasi, layanan, dan prototipe terkait IoT di lapangan. Tren penelitian dalam perawatan kesehatan berbasis IoT meliputi arsitektur dan platform jaringan, layanan dan aplikasi baru, interoperabilitas, dan keamanan. Selain itu, kebijakan dan pedoman telah dikembangkan untuk menyebarkan teknologi IoT di bidang medis di banyak negara dan organisasi di seluruh dunia. Namun, IoT masih dalam masa pertumbuhan di bidang perawatan kesehatan. Pada tahap ini, pemahaman menyeluruh tentang penelitian terkini tentang IoT dalam konteks perawatan kesehatan diharapkan bermanfaat bagi berbagai pemangku kepentingan yang tertarik dalam penelitian 
lebih lanjut. Makalah ini meneliti tren dalam penelitian perangkat berbasis IoT dengan teknologi terkait di bidang kesehatan melalui inovasi IoT.

\section{INTERNET OF THINGS PADA BIDANG KESEHATAN}

Perawatan medis dan perawatan kesehatan merupakan salah satu area aplikasi paling menarik untuk IoT [4]. IoT memiliki potensi untuk memunculkan banyak aplikasi medis seperti pemantauan kesehatan jarak jauh, program kebugaran, penyakit kronis, dan perawatan lansia. Kepatuhan dengan perawatan dan pengobatan di rumah dan oleh penyedia layanan kesehatan adalah aplikasi potensial penting lainnya. Oleh karena itu, berbagai perangkat medis, sensor, dan perangkat diagnostik dan pencitraan dapat dilihat sebagai perangkat pintar atau objek yang merupakan bagian inti dari IoT. Layanan kesehatan berbasis IoT diharapkan dapat mengurangi biaya, meningkatkan kualitas hidup, dan memperkaya pengalaman pengguna. Dari perspektif penyedia layanan kesehatan, IoT berpotensi mengurangi waktu henti perangkat melalui penyediaan jarak jauh.

IoT adalah paradigma yang muncul untuk konektivitas nirkabel dan sub-sistem sensor. IoT memungkinkan perangkat yang dapat dipakai untuk menukar (mengirim dan menerima) data secara langsung dengan layanan berbasis web yang sesuai untuk tindakan segera (jika terjadi keadaan darurat), analisis atau penyimpanan untuk digunakan nanti [5]. Cara komunikasi yang paling umum adalah pola device-to-edge (gateway) yang dapat dipakai di mana data yang dikumpulkan dikirim, pada tahap pertama, melalui protokol komunikasi nirkabel berdaya rendah jarak pendek ke perangkat seluler yang dilengkapi dengan konektivitas yang dapat dialihkan seperti sebagai Wi-Fi atau 3G / LTE. Pemrosesan otomatis data yang dikumpulkan oleh sensor kemudian dilakukan baik secara lokal pada perangkat tepi yang terletak di sekitar pasien atau di awan [5]. Gambar. 1 merupakan contoh ilustrasi dari metode tersebut.

Selain itu, IoT dapat mengidentifikasi waktu optimum dengan benar untuk mengisi ulang suplai untuk berbagai perangkat agar operasinya lancar dan berkelanjutan. Lebih lanjut, IoT menyediakan penjadwalan efisien sumber daya terbatas dengan memastikan penggunaan terbaik dan layanan lebih banyak pasien. Gambar 2 menggambarkan tren perawatan kesehatan terbaru [6]. Kemudahan interaksi yang hemat biaya melalui konektivitas yang mudah dan aman antar pasien, klinik, dan organisasi layanan kesehatan merupakan tren penting. Jaringan layanan kesehatan terkini yang didorong oleh teknologi nirkabel diharapkan dapat mendukung penyakit kronis, diagnosis dini, pemantauan waktu nyata, dan darurat medis. Gateway, server medis, dan database kesehatan memainkan peran penting dalam membuat catatan kesehatan dan memberikan layanan kesehatan sesuai permintaan kepada pemangku kepentingan yang berwenang.

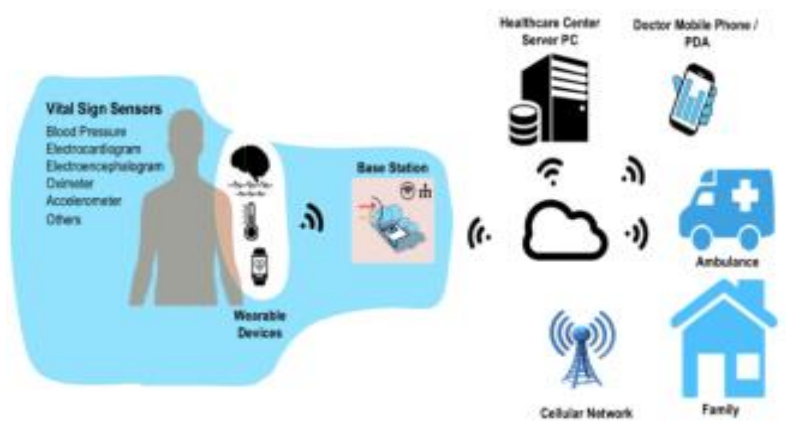

Gambar 1 Ilustrasi Hubungan Aplikasi Kesehatan IoT 


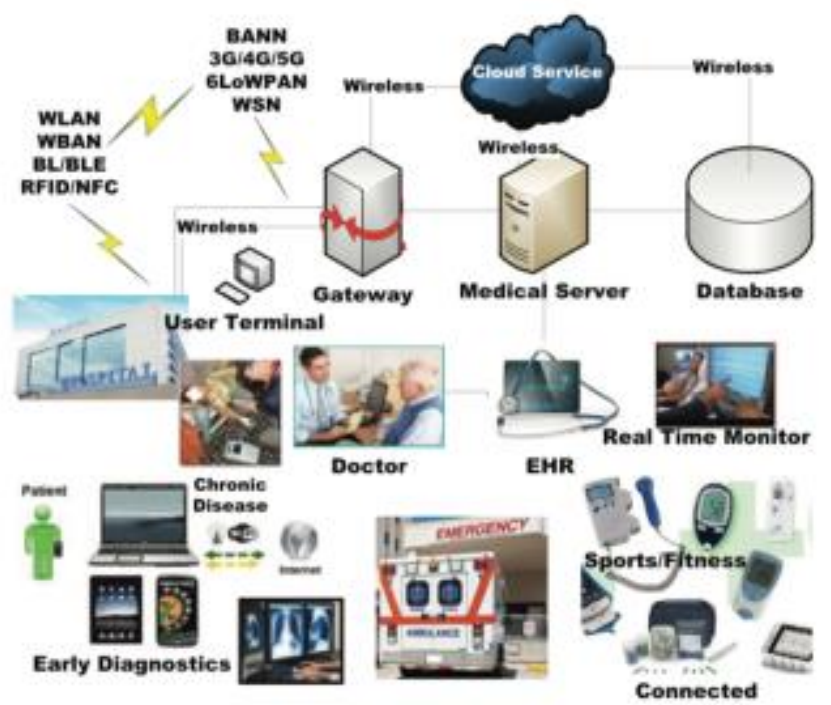

Gambar 2 Tren Perawatan Kesehatan

\section{JARINGAN DAN PERANGKAT IOT HEALTHCARE}

Jaringan kesehatan IoT atau jaringan IoT untuk perawatan kesehatan (selanjutnya disebut IoThNet) adalah salah satu elemen penting dari IoT dalam perawatan kesehatan. Jaringan ini mendukung akses ke tulang punggung IoT, memfasilitasi transmisi dan penerimaan data medis, dan memungkinkan penggunaan komunikasi yang dirancang khusus untuk perawatan kesehatan. Seperti yang ditunjukkan pada Gambar 3, bagian ini membahas topologi, arsitektur, dan platform IoThNet [7].

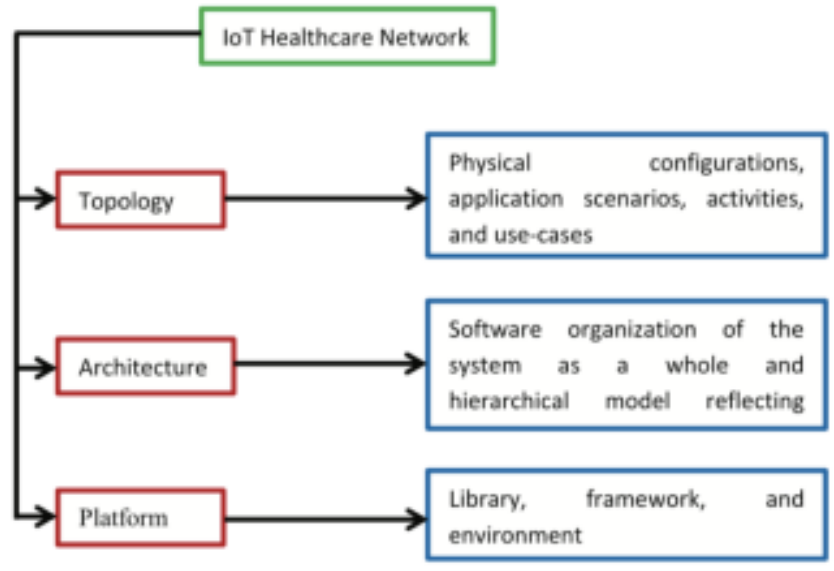

Gambar 3 Jaringan IoT Healthcare : Topologi, Arsitektur, Platform

\section{A. Topologi IoThNet}

Topologi IoThNet mengacu pada pengaturan berbagai elemen jaringan kesehatan IoT dan menunjukkan skenario yang representatif dari lingkungan perawatan kesehatan yang baik. Gambar 4 menjelaskan bagaimana grid komputasi heterogen mengumpulkan sejumlah besar tanda-tanda vital dan data sensor seperti tekanan darah (BP), suhu tubuh, elektrokardiogram (ECG), dan saturasi oksigen dan membentuk topologi khas IoThNet. Grid ini mengubah komputasi heterogen dan kemampuan penyimpanan perangkat elektronik statis dan mobile seperti laptop, smartphone, dan terminal medis menjadi grid komputasi hybrid [8]. 


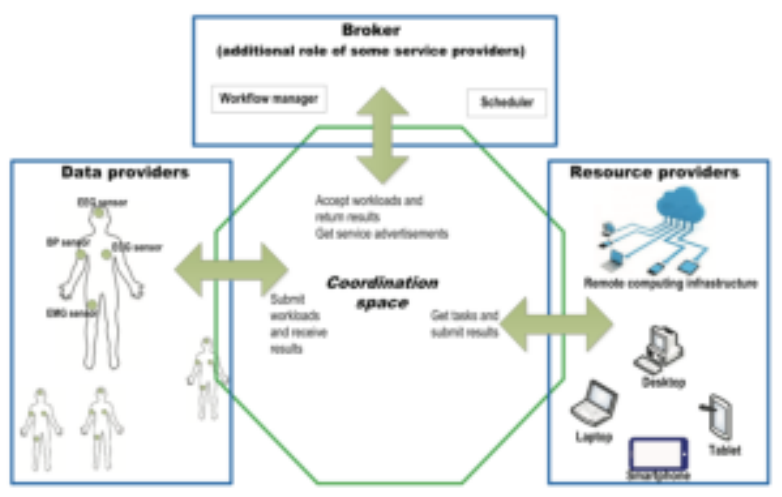

Gambar 4 Diagram Konseptual Solusi IoT Healthcare

Kemudian pada Gambar 5 memvisualisasikan skenario di mana profil kesehatan dan tandatanda vital pasien ditangkap menggunakan perangkat medis portabel dan sensor yang melekat pada tubuhnya. Data yang diambil kemudian dianalisis dan disimpan, dan data yang disimpan dari berbagai sensor dan mesin berguna untuk agregasi. Berdasarkan analisis dan agregasi, perawat dapat memantau pasien dari lokasi mana pun dan merespons dengan tepat. Selain itu, topologi mencakup struktur jaringan yang diperlukan untuk mendukung streaming video medis. Misalnya, topologi pada Gambar 6 mendukung streaming video USG melalui jaringan yang saling berhubungan dengan interoperabilitas di seluruh dunia untuk akses gelombang mikro (WiMAX), jaringan protokol internet (IP), dan sistem global untuk jaringan seluler (GSM) juga seperti gateway biasa dan akses jaringan layanan. Struktur konseptual serupa ditemukan dalam [9]-[12].

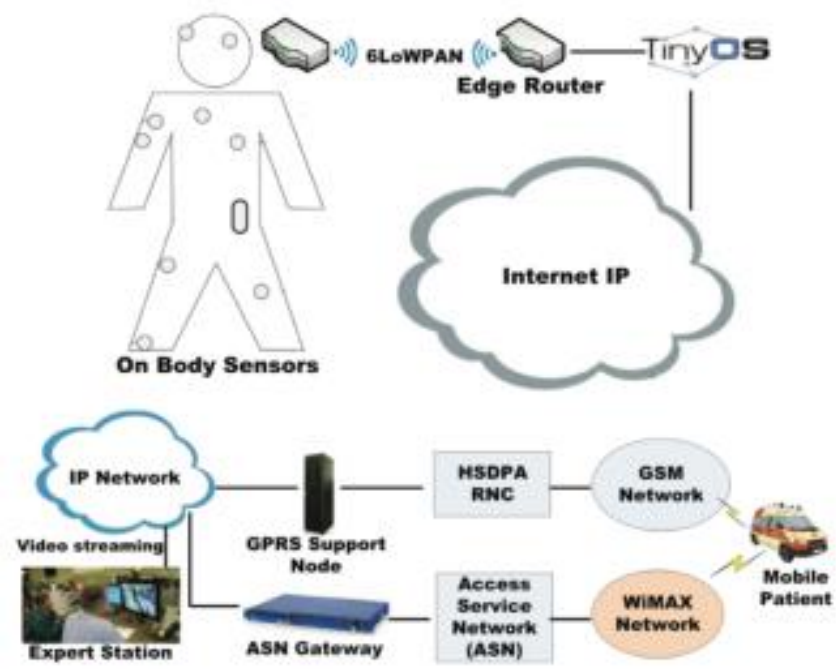

Gambar 5 Pemantauan Jarak Jauh yang Digunakan dan Dapat Dipersonalisasi dalam Bidang Kesehatan

\section{B. Arsitektur IoThNet}

Secara garis besar arsitektur IoThNet mengacu pada spesifikasi elemen-elemen fisik IoThNet, fungsi organisasi, dan prinsip serta teknik kerjanya. Sebagai permulaan, arsitektur referensi dasar pada Gambar 6 disajikan dalam sistem dengan bantuan telehealth dan ambien yang direkomendasikan oleh Continua Health Alliance. Masalah utama telah diidentifikasi untuk arsitektur ini [13]: interoperabilitas gateway IoT dan jaringan area lokal nirkabel (WLAN) / jaringan area pribadi nirkabel (WPAN), streaming multimedia, dan komunikasi yang aman antara gateway IoT dan perawat. 


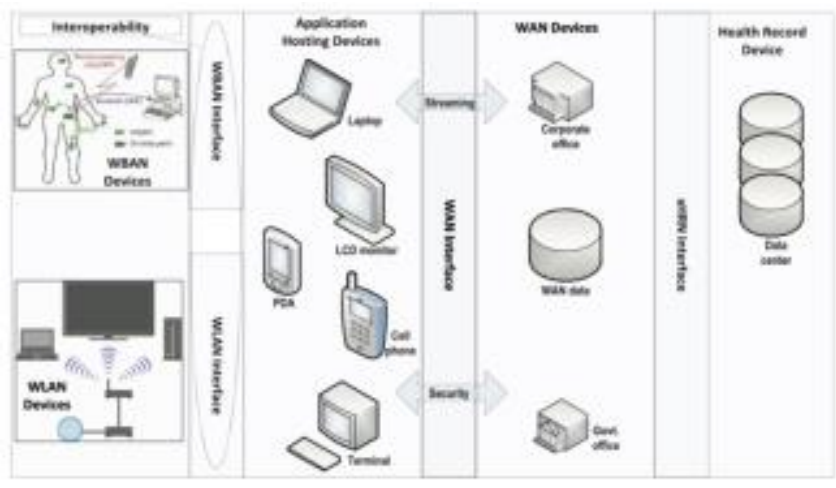

Gambar 6 Referensi Arsitektur berdasarkan Kerangka Kerja Continua Health Alliance

Banyak penelitian [10], [14]-[23] telah membenarkan bahwa 6LoWPAN berbasis IPv6 adalah dasar dari IoThNet. Seperti yang telah dirancang, Gambar 7 menunjukkan struktur lapisan 6LoWLAN. Menurut konsep IoThNet, sensor dan perangkat yang dapat dipakai menggunakan sistem IPv6 dan 6LoWPAN untuk transmisi data melalui protokol 802.15.4. Data kemudian dijawab kembali oleh node sensor dengan bantuan protokol datagram pengguna (UDP). Namun, 6LoWPAN terbatas karena tidak mendukung IPv6 seluler (MIPv6), bagian dari protokol IPv6 dengan mobilitas. Untuk memperkenalkan ketentuan mobilitas ke 6LoWPAN, sebuah protokol untuk bertukar pesan antara node pasien bergerak, jaringan dasar, dan jaringan yang dikunjungi diusulkan dalam [18].

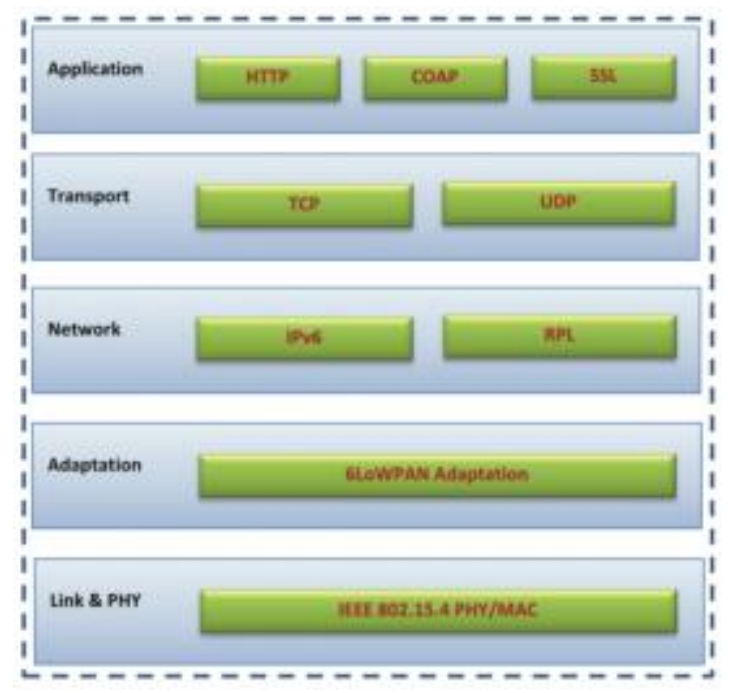

Gambar 7 Stack Protocol 6LoWPAN

\section{Platform IoThNet}

Platform IoThNet mengacu pada model platform jaringan dan platform komputasi. Seperti yang ditunjukkan pada Gambar 8, kerangka kerja platform layanan yang berfokus pada informasi kesehatan penghuni disajikan dalam [24]. Kerangka kerja ini menunjukkan model hierarkis sistematis tentang bagaimana pengasuh atau agen dapat mengakses berbagai database dari lapisan aplikasi dengan bantuan lapisan dukungan. Konsep serupa dari platform pusat data seperti middleware antara objek pintar dan lapisan bisnis dapat ditemukan di [25]. 


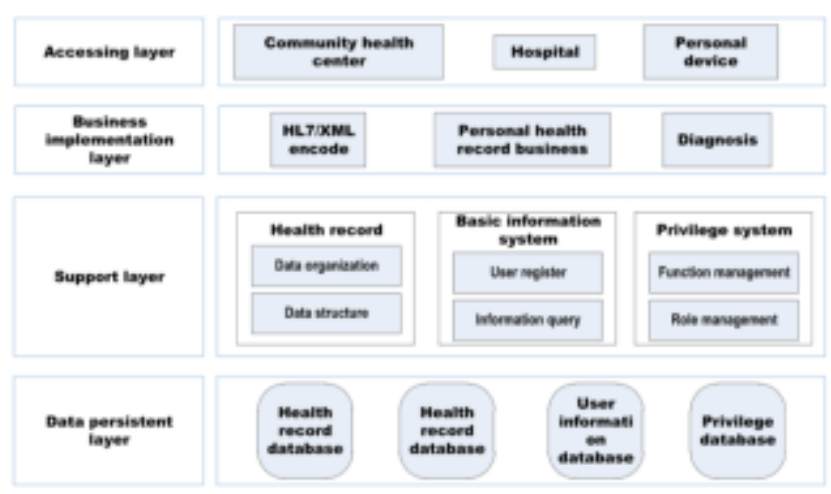

\section{Gambar 8 Kerangka Kerja Fungsional Servis Model Informasi Kesehatan}

Pentingnya standarisasi antarmuka di seluruh pemangku kepentingan IoThNet terhadap desain platform terbuka ditekankan dalam [26]. Seperti ditunjukkan pada Gambar 9, tiga kategori standardisasi antarmuka untuk membentuk ekosistem koperasi telah disajikan, termasuk antarmuka perangkat keras dan perangkat lunak, format data kesehatan (catatan kesehatan elektronik; EHR), dan skema keamanan. Ini pada akhirnya dapat memastikan interoperabilitas yang terkait. Gambaran besar platform automating design metodologi (ADM) untuk IoThNet, khususnya untuk tujuan rehabilitasi, disajikan dalam [27]. Seperti yang ditunjukkan pada Gambar 10, kerangka kerja desain ini mencakup antarmuka manusia-mesin, optimasi multidisiplin, dan manajemen aplikasi.

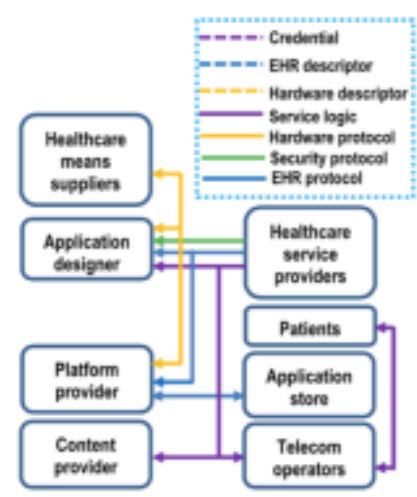

(a)

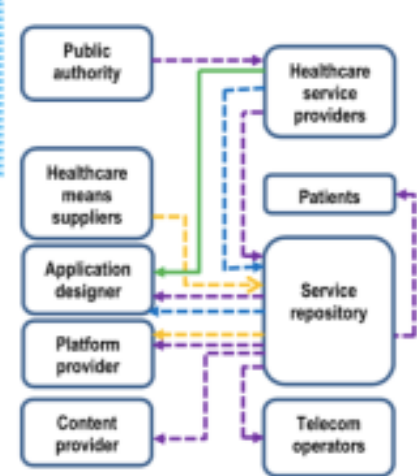

(b)

Gambar 9 Antarmuka Platform (a) Tanpa Standarisasi (b) Dengan Standarisasi

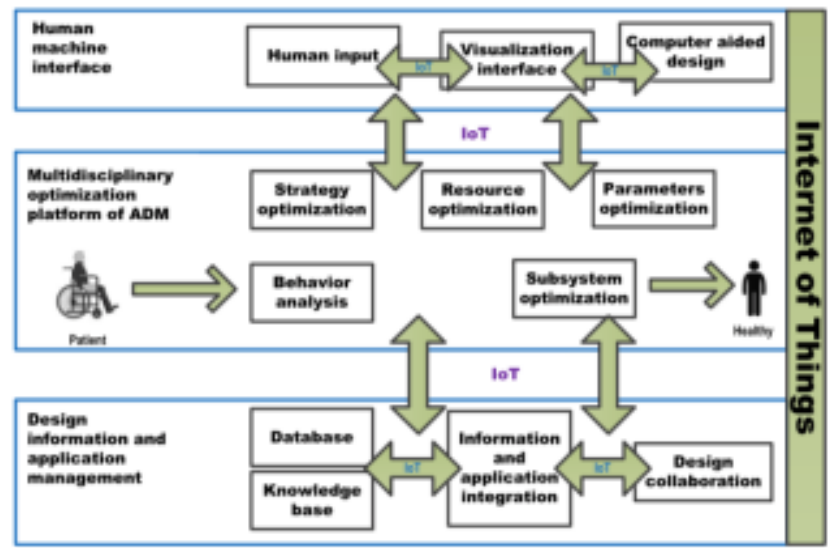

Gambar 10 Kerangka Kerja Metodologi Rancangan Otomasi 


\section{LAYANAN DAN APLIKASI IOT HEALTHCARE}

Sistem kesehatan berbasis IoT dapat dilakukan di berbagai bidang, termasuk perawatan untuk anak-anak dan pasien lanjut usia, pengawasan penyakit kronis, dan manajemen kesehatan dan kebugaran, dan lainnya. Untuk pemahaman yang lebih baik dari topik yang luas ini, makalah ini secara luas mengelompokkan diskusi dalam dua aspek: layanan dan aplikasi. Aplikasi selanjutnya dibagi menjadi dua kelompok: aplikasi kondisi tunggal dan berkelompok. Aplikasi kondisi tunggal mengacu pada penyakit atau kelemahan tertentu, sedangkan aplikasi kondisi-cluster berhubungan dengan sejumlah penyakit atau kondisi secara keseluruhan. Gambar 11 mengilustrasikan kategorisasi ini. Perhatikan bahwa struktur klasifikasi ini dibingkai berdasarkan solusi perawatan kesehatan yang tersedia saat ini menggunakan IoT.

Daftar ini pada dasarnya bersifat dinamis dan dapat dengan mudah ditingkatkan dengan menambahkan layanan tambahan dengan fitur berbeda dan banyak aplikasi yang mencakup solusi kondisi tunggal dan berkerumun. Bagian ini memperkenalkan setiap layanan dan aplikasi yang ditunjukkan pada gambar tersebut.

\section{A. Layanan Healthcare IoT}

IoT diantisipasi untuk memungkinkan berbagai layanan kesehatan di mana setiap layanan menyediakan serangkaian solusi perawatan kesehatan. Dalam konteks perawatan kesehatan, tidak ada definisi standar layanan IoT. Namun, mungkin ada beberapa kasus di mana suatu layanan tidak dapat dibedakan secara objektif dari solusi atau aplikasi tertentu.

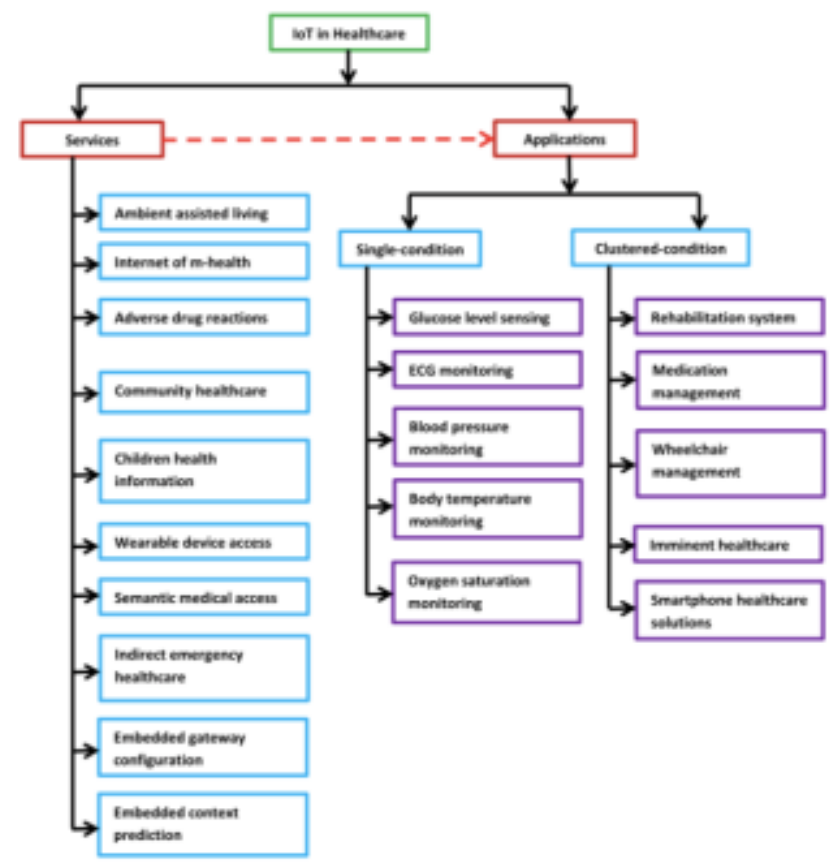

\section{Gambar 11 Layanan dan Aplikasi IoT Healthcare}

Selain itu, perlu dicatat bahwa layanan umum dan protokol yang diperlukan untuk kerangka kerja IoT mungkin memerlukan sedikit modifikasi agar berfungsi dengan baik dalam skenario perawatan kesehatan. Hal ini termasuk layanan notifikasi, layanan berbagi sumber daya, layanan internet, protokol lintas konektivitas untuk perangkat heterogen, dan protokol tautan untuk konektivitas utama [7]. Berikut ini adalah beberapa tipe atas layanan IoT Healthcare :

1) Ambient Assisted Living (AAL)

2) The Internet of M-Health Things (M-IoT) 
3) Adverse Drug Reaction (ADR)

4) Community Healthcare $(\mathrm{CH})$

5) Children Health Information (CHI)

6) Wearable Device Access (WDA)

7) Semantic Medical Access (SMA)

8) Indirect Emergency Healthcare (IEH)

9) Embedded Gateway Configuration (EGC)

10) Embedded Context Prediction (ECP)

\section{B. Aplikasi IoT Healthcare}

Selain layanan IoT, aplikasi IoT patut mendapatkan perhatian lebih. Dapat dicatat bahwa layanan digunakan untuk mengembangkan aplikasi, sedangkan aplikasi secara langsung digunakan oleh pengguna dan pasien. Oleh karena itu, layanan bersifat developer-centric, sedangkan aplikasi, user-centric. Selain aplikasi yang dicakup dalam bagian ini, berbagai gadget, perangkat yang dapat dikenakan, dan perangkat kesehatan lain yang saat ini tersedia di pasar akan didiskusikan. Produk-produk ini dapat dipandang sebagai inovasi IoT yang dapat mengarah pada berbagai solusi perawatan kesehatan. Berikut ini adalah berbagai aplikasi perawatan kesehatan berbasis IoT, termasuk aplikasi kondisi tunggal dan berkelompok.

1) Glucose Level Sensing

2) Electrocardiogram Monitoring

3) Blood Pressure Monitoring

4) Body Temperature Monitoring

5) Oxygen Saturation Monitoring

6) Rehabilitation System

7) Medication Management

8) Wheelchair Management

9) Imminent Healthcare Solutions

10) Healthcare Solutions Using Smartphones

IoT yang muncul di bidang perawatan kesehatan telah mengalami lonjakan aktivitas dan kreativitas, pengusaha dan perusahaan modal ventura. Aktivitas itu muncul sebagai kelompok aktif dari perusahaan baru dan perusahaan besar yang bersedia menjadi bagian dari apa yang mungkin menjadi pasar raksasa terkait produk dan teknologi. Gambar 12 menunjukkan koleksi representatif dari produk perawatan kesehatan berbasis IoT saat ini. 


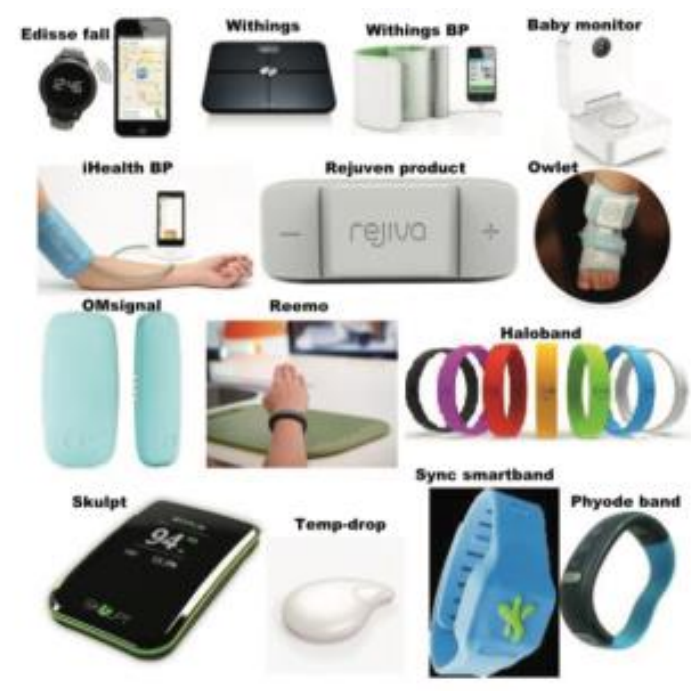

Gambar 12 Contoh Produk dan Prototipe IoT Healthcare

Meskipun ada banyak aplikasi oleh pengembang di seluruh dunia, makalah ini membahas beberapa aplikasi yang dipilih berdasarkan jenis, popularitas, dan analisis intuitif. Sebagian besar aplikasi yang tercantum di sini dapat digunakan dengan mudah.

\section{Teknologi IoT Healthcare}

Ada banyak teknologi yang memberikan solusi perawatan kesehatan berbasis IoT, oleh karena itu sulit untuk menyiapkan daftar eksplisit. Dalam hal ini, diskusi berfokus pada beberapa teknologi inti yang memiliki potensi untuk merevolusi layanan kesehatan berbasis IoT. Berikut adalah teknologi yang dibahas dalam makalah ini.

a. Cloud Computing

Integrasi cloud computing ke dalam teknologi perawatan kesehatan berbasis IoT menyediakan fasilitas dengan akses dimanapun dengan berbagi sumber daya, menawarkan layanan berdasarkan permintaan melalui jaringan dan menjalankan operasi untuk memenuhi berbagai kebutuhan.

b. Grid Computing

Kemampuan komputasi node sensor medis yang tidak memadai dapat diatasi dengan memperkenalkan komputasi grid ke jaringan layanan kesehatan. Komputasi grid, komputasi cluster yang lebih akurat, dapat dipandang sebagai tulang punggung komputasi awan.

c. Big Data

Data besar dapat mencakup sejumlah besar data kesehatan esensial yang dihasilkan dari beragam sensor medis dan menyediakan alat untuk meningkatkan efisiensi diagnosis kesehatan serta metode dan tahapan pemantauan.

d. Network

Berbagai jaringan mulai dari jaringan untuk komunikasi jarak dekat (misalnya, WPAN, WBAN, WLAN, 6LoWPANs, dan WSNs) hingga komunikasi jarak jauh (misalnya, semua jenis jaringan seluler) adalah bagian dari infrastruktur fisik dari layanan kesehatan berbasis IoT jaringan. Selain itu, penggunaan teknologi ultrawideband (UWB), BLE, NFC, dan RFID dapat membantu merancang perangkat sensor medis berdaya rendah serta protokol komunikasi.

e. Ambient Intelligence

Penerapan kecerdasan ambient sangat penting karena pengguna akhir, klien, dan pelanggan dalam jaringan perawatan kesehatan adalah manusia (pasien atau individu yang sadar kesehatan. Ambient intelligence memungkinkan pembelajaran terus 
menerus tentang perilaku manusia dan mengeksekusi semua tindakan yang diperlukan yang dipicu oleh kejadian dan peristiwa. Integrasi kontrol otonom dan teknologi interaksi komputer manusia (HCI) ke dalam ambient intelligence dapat lebih meningkatkan kemampuan layanan kesehatan yang dibantu IoT.

f. Augmented Reality

Menjadi bagian dari IoT, augmented reality memainkan peran kunci dalam rekayasa kesehatan. Augmented reality berguna antara lain untuk operasi dan pemantauan jarak jauh.

g. Wearables

Keterlibatan pasien dan peningkatan kesehatan populasi dapat difasilitasi dengan merangkul perangkat medis yang dapat dipakai sebagai landmark. Ini memiliki tiga manfaat utama: informasi yang terhubung, komunitas layanan kesehatan yang berorientasi pada target, dan gamifikasi.

\section{KESIMPULAN}

Internet of Things di bidang kesehatan telah membantu menghasilkan solusi teknologi dalam meningkatkan layanan kesehatan. Banyak peneliti telah mengeksplorasi berbagai teknologi dengan memobilisasi potensi IoT. Makalah ini mensurvei beragam aspek teknologi terkait perangkat IoT dalam bidang kesehatan dengan menyajikan arsitektur dan platform jaringan yang mendukung akses ke tulang punggung IoT dan memfasilitasi transmisi dan penerimaan data medis. Untuk pengembangan lebih lanjut mengenai tren industri dan teknologi yang memungkinkan, makalah ini memberikan pandangan luas tentang bagaimana kemajuan terkini dan berkelanjutan pada sensor, perangkat, aplikasi internet, dan teknologi lainnya.

\section{DAFTAR PUSTAKA}

[1] M. O. Ojo, S. Member, S. Giordano, S. Member, G. Procissi, dan I. N. Seitanidis, "A Review of Low-End , Middle-End, and High-End Iot Devices," IEEE Access, vol. 6, hal. 70528-70554, 2018.

[2] J. Gubbi, R. Buyya, S. Marusic, dan M. Palaniswami, "Internet of Things ( IoT ): A vision, architectural elements , and future directions," Futur. Gener. Comput. Syst., vol. 29, no. 7, hal. 1645-1660, 2013.

[3] A. T. Thakar dan S. Pandya, "Survey of iot enables healthcare devices," Proc. Int. Conf. Comput. Methodol. Commun. ICCMC 2017, vol. 2018-January, no. Iccmc, hal. 1087-1090, 2018.

[4] Z. PANG, Technologies and Architectures of the Internet-of-Things (IoT) for Health and Well-being ZHIBO PANG Doctoral Thesis in Electronic and Computer Systems, no. January. 2013.

[5] D. Minoli, Building the Internet of Things with IPv6 and MIPv6. 2013.

[6] K. Vasanth dan J. Sbert, "Creating solutions for health through technology innovation," hal. 1-7, 2014.

[7] S. M. R. Islam, D. Kwak, M. H. Kabir, M. Hossain, dan K. S. Kwak, "The internet of things for health care: A comprehensive survey," IEEE Access, vol. 3, hal. 678-708, 2015.

[8] H. Viswanathan, E. K. Lee, dan D. Pompili, "Mobile Grid Computing for Data- and Patient-centric Ubiquitous Healthcare," hal. 653-658, 2012.

[9] R. S. H. Istepanian, "The Potential of Internet of Things ( IOT ) for Assisted Living 
Applications - Mega Trends in Healthcare and IT New m-IOT Concept Exemplars of m-IOT in assisted living Future trends," no. April, 2011.

[10] S. Imadali, A. Karanasiou, A. Petrescu, dan I. Sifniadis, "EHealth Service Support In IPv6 Vehicular Networks," 2012 IEEE 8th Int. Conf. Wirel. Mob. Comput. Netw. Commun., hal. 579-585, 2020.

[11] N. Yang, X. Zhao, dan H. Zhang, "A non contact health monitoring based on the Internet of Things," 2012 8th Int. Conf. Nat. Comput., no. Icnc, hal. 506-510, 2012.

[12] W.Zhao, W. Chaowei, dan Y. Nakahira, "Medical application on Internet of Things," Proc. IET Int. Conf. Commun. Technol. Appl. (ICCTA), hal. 660-665, 2011.

[13] X. M. Zhang dan N. Zhang, "An open, secure and flexible platform based on internet of things and cloud computing for ambient aiding living and telemedicine," 2011 Int. Conf. Comput. Manag. CAMAN 2011, hal. 1-4, 2011.

[14] R. Tabish et al., "A 3G/WiFi-enabled 6LoWPAN-based U-healthcare system for ubiquitous real-time monitoring and data logging," Middle East Conf. Biomed. Eng. MECBME, hal. 277-280, 2014.

[15] A. J. Jara, A. F. Alcolea, M. A. Zamora, A. F. G??mez Skarmeta, dan M. Alsaedy, "Drugs interaction checker based on IoT," 2010 Internet Things, IoT 2010, 2010.

[16] M. F. A. Rasid et al., "Embedded gateway services for Internet of Things applications in ubiquitous healthcare," 2014 2nd Int. Conf. Inf. Commun. Technol. ICoICT 2014, hal. 145-148, 2014.

[17] P. Lopez, D. Fernandez, A. J. Jara, dan A. F. Skarmeta, "Survey of internet of things technologies for clinical environments," Proc. - 27th Int. Conf. Adv. Inf. Netw. Appl. Work. WAINA 2013, hal. 1349-1354, 2013.

[18] M. S. Shahamabadi, B. B. M. Ali, P. Varahram, dan A. J. Jara, "A network mobility solution based on 6LoWPAN hospital wireless sensor network (NEMO-HWSN)," Proc. - 7th Int. Conf. Innov. Mob. Internet Serv. Ubiquitous Comput. IMIS 2013, hal. 433-438, 2013.

[19] A. J. Jara, M. A. Zamora-Izquierdo, dan A. F. Skarmeta, "Interconnection framework for mHealth and remote monitoring based on the Internet of Things," IEEE J. Sel. Areas Commun., vol. 31, no. 9, hal. 47-65, 2013.

[20] A. J. Jara, M. A. Zamora, dan A. F. Skarmeta, "Knowledge acquisition and management architecture for mobile and personal health environments based on the Internet of things," Proc. 11th IEEE Int. Conf. Trust. Secur. Priv. Comput. Commun. Trust. - 11th IEEE Int. Conf. Ubiquitous Comput. Commun. IUCC-2012, hal. 1811$1818,2012$.

[21] C. Doukas dan I. Maglogiannis, "Bringing IoT and cloud computing towards pervasive healthcare," Proc. - 6th Int. Conf. Innov. Mob. Internet Serv. Ubiquitous Comput. IMIS 2012, hal. 922-926, 2012.

[22] N. Bui, N. Bressan, dan M. Zorzi, "Interconnection of body area networks to a communications infrastructure: An architectural study," Eur. Wireless, 2012. EW. 18th Eur. Wirel. Conf., hal. 1-8, 2012.

[23] R. S. H. Istepanian, S. Hu, N. Y. Philip, dan A. Sungoor, "The potential of Internet of m-health Things m-IoT for non-invasive glucose level sensing," Proc. Annu. Int. Conf. IEEE Eng. Med. Biol. Soc. EMBS, hal. 5264-5266, 2011.

[24] W. Wang, J. Li, L. Wang dan W. Zhao, "The Internet of Things for resident health information service platform research,' Proc. IET Int. Conf. Commun. Technol. Appl. (ICCTA), hal 631-635, 2011

[25] L. Yang, Y. Ge, W. Li, W. Rao, dan W. Shen, "A home mobile healthcare system for wheelchair users," Proc. 2014 IEEE 18th Int. Conf. Comput. Support. Coop. Work Des. CSCWD 2014, hal. 609-614, 2014. 
[26] Z. Pang dan J. Tian, "Ecosystem Analysis in the Design of Open Platform based InHome Healthcare Terminals towards the Internet-of-Things," 15th Int. Conf. Adv. Commun. Technol., hal. 529-534, 2013.

[27] Yuan Jie Fan, Yue Hong Yin, Li Da Xu, Yan Zeng, dan Fan Wu, "IoT-Based Smart Rehabilitation System," IEEE Trans. Ind. Informatics, vol. 10, no. 2, hal. 1568-1577, 2014. 